\title{
Sustained GDNF delivery via PLGA nanoparticles
}

Pablo Vicente Torres-Ortega ${ }^{1,2}$, Cristian Smerdou ${ }^{2,3}$, Elisa Garbayo ${ }^{1,2}$, María J. Blanco Prieto ${ }^{1,2 *}$

\section{INTRODUCTION}

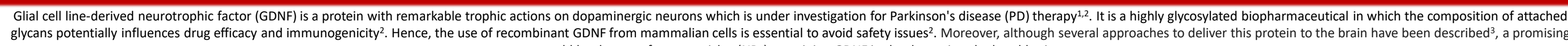
strategy would be the use of nanoparticles (NPs) containing GDNF in the dopamine-depleted brain areas.

The objective of this work is to develop and characterize biodegradable NPs loaded with recombinant GDNF produced in mammalian cells for brain tissue engineering.

RESULTS

hGDNF expression and purification

A) hGDNF expression in BHK cells

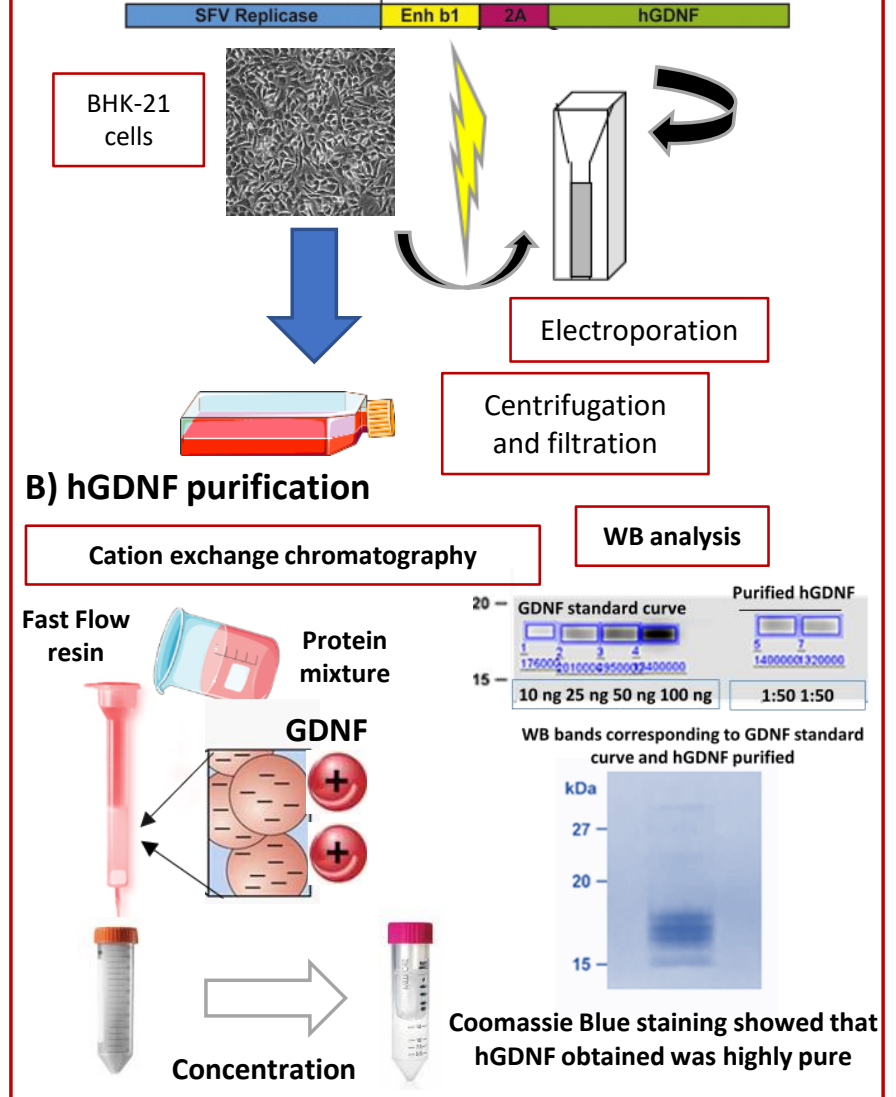

\section{hGDNF-loaded NPs preparation and characterization}

A) hGDNF-loaded NPs preparation

B) NPs characterization

hGDNF-NPs were formulated by double emulsión

solvent evaporation using One Recirculation

Machine (TROMS) Technology

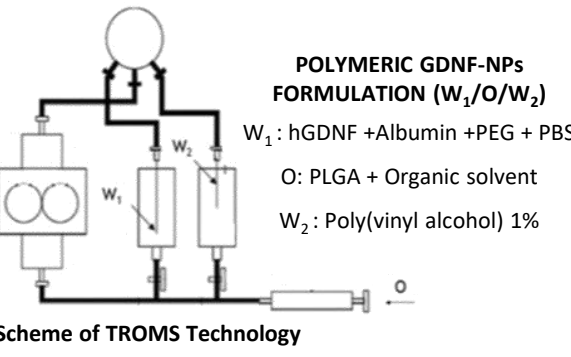

B4 In vitro release study of GDNF from NPs

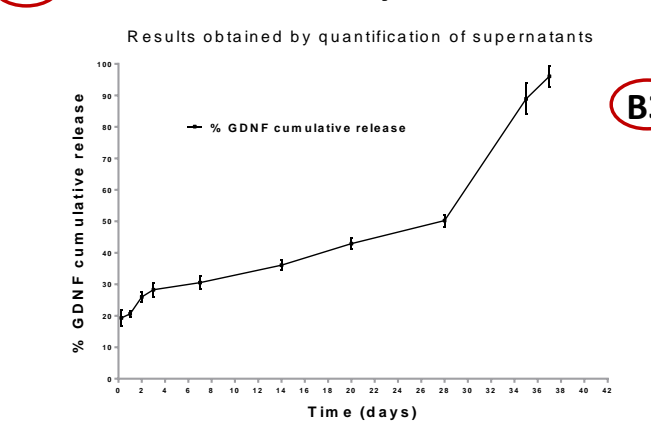

GDNF released within the first 24 hours was $19.10 \pm 3.5 \%$ followed by a phase of sistint of GDNF being released within 28 days. Uniform size distribution of NPs.
(B1) Size, PDI and EE

\begin{tabular}{l|l|l|l}
\hline PLGA & MEAN SIZE & PDI & EE\% \\
\hline
\end{tabular}
\begin{tabular}{l|l|l|l} 
NPs $(n=3)$ & $405.5 \pm 2.9 \mathrm{~nm}$ & $0.08 \pm 0.03$ & $61.65 \pm 7$
\end{tabular}

B2 SEM analysis

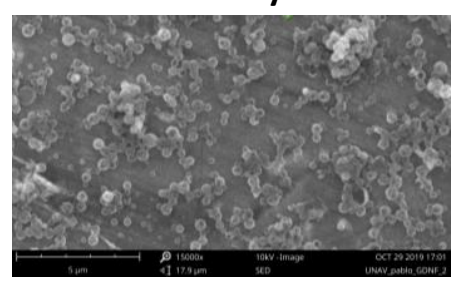

Spherical particles. No aggregation.

B3. Bioactivity

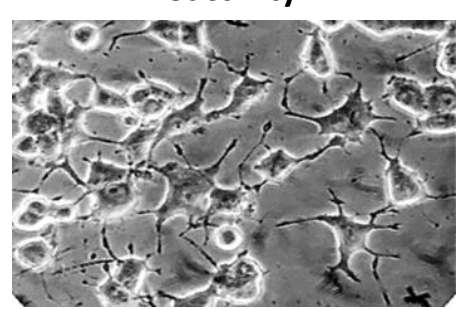

PC12 cell-based bioassay showed that nanoencapsulation.

\section{Future perspectives}

- A two-component hydrogel based on HA functionalization with adamantane (guest) and $\beta$-cyclodextrin (host) will be prepared and characterized.

GDNF-NPs will be included in the hydrogel for its local brain administration.

\section{CONCLUSIONS}

- GDNF-loaded NPs were successfully prepared by W1/O/W2 emulsion/extraction process using TROMS technology with a high drug entrapment efficiency.

- The developed nanosystem has great potential for brain tissue engineering applications.

\section{REFERENCES}

1. E. Garbayo et al, Effective GDNF brain delivery using microspheres-A promisin strategy for Parkinson's disease.

2. R.A. Barker et al, GDNF and Parkinson's Disease: Where Next? A Summary from Recent Workshop.

3. P.V. Torres-Ortega et al, Micro- and nanotechnology approaches to improve Parkinson's disease therapy.

4. E. Ansorena et al. A simple and efficient method for the production of human glycosylated glial cell line-derived neurotrophic factor using a Semliki Forest virus

\section{ACKNOWLEDGEMENTS}

This work was supported by the Spanish Ministry of Education (program FPU (FPU17/01212)) and Government of Navarra (2019_66_NAB9). E. Garbayo is supported by a "Ramon y Cajal Fellowship (RYC2018-025897-I). 